\title{
Collaborative learning of new information in older age: a systematic review
}

Kelly Wolfe, Catherine J. Crompton, Paul Hoffman \& Sarah E. MacPherson

\begin{abstract}
Aging is accompanied by a multitude of changes in cognitive abilities such as processing speed and memory, which in turn affect learning. Learning collaboratively may benefit older adults by negating some of these age-related changes. Collaborative learning, especially in older age, has not been extensively studied but is experiencing a resurgence. However, studies in the literature differ in both their methodology and findings and a comprehensive overview of research conducted on collaborative learning does not exist. As such, this manuscript proposes a systematic review of the current research on collaborative learning in older age, exploring under which circumstances collaborative learning can be more beneficial compared to learning individually. The proposed project will provide insight into learning in later life, as well as identify gaps in current knowledge and outstanding issues to address in future research.
\end{abstract}




\section{Introduction}

Generally, society holds conflicting beliefs about older age; with older age comes wisdom, but also a decline in cognitive functioning. Though seemingly contrary, research has found that both beliefs can co-exist; older adults are found to experience more emotional stability (Williams et al., 2006), show signs of increased positivity (Ashby et al., 1999; Kim et al., 2008), and yet experience declines in cognitive functions such as processing speed, executive functions, and memory (Salthouse et al., 2003; Salthouse \& Craik, 2007). Those cognitive abilities are associated with the ability to learn new information and skills, and age-related decline can result

in older adults experiencing learning difficulties (Craik, 2021). In general, learning is studied as a solitary process, in which a person's ability to learn is measured in an experimental setting, using a task with specific instructions on which information or skill to learn. Yet, in daily life, people often learn through interacting with others, or by working collaboratively on obtaining knowledge. Learning collaboratively may be especially beneficial in older age as it could negate age-related effects on learning. For example, findings by Derksen et al. (2015) showed that older adults performed similarly to younger adults on a memory task when learning collaboratively. As such, it is advantageous to investigate the degree to which collaborative learning benefits older adults, as well as the circumstances under which this occurs.

\section{Age-related effects on abilities associated with learning}

The ability to learn requires multiple cognitive processes including encoding, maintaining, and retrieving knowledge, some of which are affected by age. Even though age-related effects on memory, reasoning, and speed appear most pronounced after the sixth decade (Salthouse, 2004; Schaie, 1996), some age-related effects can be found in middle age (Garden et al., 2001) or even earlier (Salthouse, 2004). In addition, the age-related effects on cognitive abilities such as processing speed and working memory can be substantial (Park et al., 2002). Processing 
speed has an indirect effect on learning in older age; being older is related to lower processing speed, which is then related to lower accuracy when learning new information, which in turn is associated with higher rates of forgetting (Salthouse, 1994). Processing speed has been found to affect the relationship between older age and multiple cognitive processes (Li et al., 2004; Li et al., 2013; Park et al., 2002; Salthouse, 1994, 1996), including working memory (Hedden et al., 2005). Working memory is the cognitive system responsible for temporarily holding information and using it for the execution of cognitive tasks, and is related to information processing, comprehension, problem-solving, and learning (Cowan, 2014). Prior research has shown that older adults are likely to experience a decline in working memory (Bopp \& Verhaeghen, 2005; Elliott et al., 2011; Grégoire \& Linden, 1997; Hale et al., 2011; Myerson et al., 2003; Park et al., 2002), with Elliott et al. (2011) reporting that older adults experienced increased difficulty across all working memory tasks in their study. A decline in working memory can affect performance on a learning task, such as not being able to remember instructions (Jaroslawska et al., 2021), or not being able to assess relationships between pieces of information or create new associations. These difficulties may manifest due to an impairment in the encoding, maintenance, or retrieval stage of working memory (Halford et al., 1998).

\section{Negating age-effects on memory}

However, age-related effects on memory can be reduced under certain conditions. If the information is emotional by nature, older adults remembered a similar amount of information to younger adults (Denburg et al., 2003; Kensinger, 2008). For example, Comblain et al. (2004) found that older and younger adults performed similarly when recognizing emotional information, with older adults recognizing stimuli due to their own emotional response when the information was presented to them at the time. Another approach to reducing age-related effects on memory is through inducing mood (Ashby et al., 1999). Grady et al. (2007) found that older adults recognized more positive and negative faces when they were in a positive mood, 
while Knight et al. (2002) found that older adults remembered sad information better when a negative mood was induced. In addition, when non-declarative memory is involved, older adults retain a similar amount of knowledge to younger adults when learning a skill (Chauvel et al., 2012; Romano et al., 2010). Lastly, working collaboratively in a social setting could negate ageeffects on memory. Existing research has highlighted the relationship between social engagement and cognitive well-being, with low social engagement associated with a higher likelihood of cognitive decline (Evans et al., 2019; Zahodne et al., 2019; Zunzunegui et al., 2003). Some studies have found evidence that age-related effects on memory can be negated through collaboration (Dixon \& Gould, 1996; Martin \& Wight, 2008; Strough \& Margrett, 2002).

\section{Collaborative recall}

We often collaborate with others to remember an event or experience and many studies have investigated remembering, or recall, as a collaborative experience. Typically, in such studies, participants co-operate to recall information that they obtained previously, either individually or as part of a pair or larger group. These pairs or groups can consist of strangers (Andersson \& Rönnberg, 1995, 1996; Bärthel et al., 2017; Browning et al., 2019; Selwood et al., 2020; Vredeveldt et al., 2019), friends (Andersson \& Ronnberg, 1997; Andersson \& Rönnberg, 1995, 1996; Selwood et al., 2020; Vredeveldt et al., 2019), siblings (Selwood et al., 2020) or romantic partners (Barnier et al., 2018; Browning et al., 2019; Harris et al., 2011; Johansson et al., 2005). The information to be recalled differs, and study materials range from a list of words without personal relevance (Andersson \& Ronnberg, 1997; Harris et al., 2011; Johansson et al., 2005), actions within a computerized memory task (Browning et al., 2019), video materials (Andersson \& Rönnberg, 1995; Bärthel et al., 2017; Vredeveldt et al., 2019), a list with items of personal relevance (Harris et al., 2011), stories (Andersson \& Rönnberg, 1995; Johansson et al., 2005), and autobiographical interviews (Harris et al., 2011). So far, research on collaborative recall has demonstrated that remembering together can be highly beneficial compared to remembering 
individually (Bärthel et al., 2017; Meudell et al., 1995; Vredeveldt et al., 2019; Weldon \& Bellinger, 1997). Collaborative recall has been found to increase the accuracy and completeness of a memory compared to working alone (Stephenson et al., 1983) and its success was found to be stable over time (Barnier et al., 2018). Recalling collaboratively may be especially beneficial in older age, with studies showing that older adults remember more after recalling together compared to recalling alone (Blumen et al., 2013; Blumen \& Stern, 2011; Johansson et al., 2005; Peter-Wight \& Martin, 2011). In addition, the benefits of the collaborative recall over individual recall were found to still be present 7 days later, in both younger and older adults (Blumen \& Stern, 2011). The benefits associated with remembering together are mostly found in intimate pairs such as spouses (Browning et al., 2019), but the extent of success depends on factors beyond the type of relationship. Differences in the division of labor (Johansson et al., 2005), the strategies used to recall, and effective communication skills (Harris et al., 2011) can impact the extent to which collaborative recall is beneficial. Overall, the research on collaborative recall has expanded over the last two decades, including several reviews (e.g., Barnier \& Sutton, 2008; Blumen et al., 2013; Harris et al., 2008), and has demonstrated that remembering together can provide benefits in older age. If collaboration benefits older adults when they recall existing information, could it also help when they are learning new information?

\section{Collaborative learning}

Collaborative learning can be defined as cooperating and communicating with another person to learn a new skill or task, as opposed to learning alone (Dillenbourg, 1999; Dixon et al., 2008). In collaborative learning studies, cooperation occurs during the acquisition of new information or skills, rather than only during their retrieval (which applies to collaborative recall). Learning collaboratively can be done in a variety of ways. People may learn with a person familiar to them, such as a spouse or friend, or with an unfamiliar person. Pairs, as well as larger groups of 
more than 2 people, can work together to acquire new skills or information. Within these types of groups, there may be an equal (i.e., both work on the same task with the same roles) or unequal division of labor (i.e., pairs have defined but different roles within a collaborative activity). In addition, the learning process can be face-to-face or through other media, such as online or over the telephone (Dillenbourg, 1999). Like collaborative recall, a variety of materials can be used to study how people learn together. The Barrier Task (Duff et al., 2006) is such a material that has been used in collaborative learning research (Derksen et al., 2015). This joint referential task is performed by two people, who are assigned the role of Director or Matcher. They sit facing each other across a table while separated by a low barrier, which obstructs the view of the other side of the table. Each person has a board with twelve numbered spaces and twelve tangrams (which are abstract geometric shapes). The Director's tangrams are arranged in a predetermined order on their board, while those of the Matcher are not. The Director must communicate to the Matcher where the tangrams are to be placed to have two identical boards by the end of the trial. This process is completed by describing what each tangram looks like and where to place them on the board. Over time, participants learn how to complete the task more efficiently through their own acquired knowledge of the task as well as the complementary knowledge of their collaborator (i.e., utilizing the other person's labels and descriptions of the tangrams). As such, the Barrier Task is an example that clearly demonstrates how collaboration between pairs can result in new knowledge or skills.

By learning collaboratively, participants can utilize their prior knowledge, which can be shared or complimentary. Shared knowledge refers to group members having (close to) identical prior knowledge of the same topic, whereas complementary knowledge means that each collaborator provides individual knowledge of a shared topic (Canham et al., 2012).

There are two mechanisms that underlie both collaborative learning and recall, namely crosscueing and re-exposure. In cross-cueing, the recall of one group member can cue the memory of other group members (Nokes-Malach et al., 2019). For example, expert pilots recalling 
aviation scenarios together remembered more compared to the scenarios being remembered individually (Meade et al., 2009). Secondly, re-exposure to information occurs when one person provides access to learning material that would not have been available if pairs learned alone. For example, one person may not remember what they ate at a family meal the week before, but someone else present at that same dinner may remember. When information is remembered together, a person is re-exposed to the information due to their partner's recall and is more likely to remember what they had for dinner than if they remembered alone (Blumen et al., 2013).

Though there is evidence that people learn better together, some studies suggest that the collectively learned information is unlikely to be equal to the pooled performance of individual group members when remembering collaboratively (Marion \& Thorley, 2016). Pereira-Pasarin and Rajaram (2011) compared a collaborative group to a nominal group (the same number of participants remembering individually) and found that participants did not contribute as much information when learning with a partner compared to learning alone. This effect is referred to as collaborative inhibition (Rajaram, 2017; Weldon \& Bellinger, 1997). Collaborative inhibition likely presents due to varying retrieval strategies across participants (Finlay et al., 2000), and a lack of cross-cueing. Group members remembering collectively often do not cue each other to elicit new information, beyond what has been mentioned previously (Harris et al., 2008; Meudell et al., 1995). However, the effect of collaborative inhibition disappears when partners can work together to remember (unlike pairs recalling while together, but without any conversation between partners) (Johansson et al., 2000). In addition, collaborative inhibition has not been found when recalling semantic information; when recalling semantic information, pairs perform better together compared to individual recall (Johansson et al., 2005). In addition, pairs have been found to recall more accurate and complete information compared to individual recall (Stephenson et al., 1983). Overall, the benefit of collaborative learning may depend on other factors, such as the type of information and how pairs work together (e.g., learning together but 
remembering alone or being allowed to help the other person remember).

While children and younger adults are known to learn collaboratively (both in and outside school environments) (Golbeck \& El-Moslimany, 2013), collaborative learning may be equally prominent in older age as older adults often work together with a spouse, friend, or family member in everyday cognitive activities (Berg et al., 2003; Meade et al., 2018; Peter-Wight \& Martin, 2011) and generally view collaboration as beneficial (Henkel \& Kris, 2017). These regular experiences of working collaboratively allow for individual strengths to be applied where needed and more efficient use of the cognitive resources that are available, especially during tasks without much guidance or structure (Derksen et al., 2015). As such, collaborative learning may benefit older adults' memory performance when learning new information. In the last two decades or so, research on collaborative learning has experienced a resurgence. For example, studies on collaborative learning among patients with cognitive impairment have found that learning together improved memory performance, both in patients with Alzheimer's disease (Duff et al., 2013) and patients with amnesia due to focal hippocampal damage (Duff et al., 2006). These findings highlight the potential benefits of learning together, and how this social approach to learning may be able to negate memory decline in older age.

\section{The distinction between collaborative learning and recall}

Though collaborative learning and recall are often used interchangeably, as well as studied simultaneously, here we make a distinction between the two concepts. Collaborative recall specifically refers to the process of solely retrieving information, while collaborative learning encompasses multiple processes, including understanding, processing, and storing information, as well as being able to recall information with other people. While collaborative recall can be a part of the learning process, it does not have to be, and these two areas can be studied separately (i.e., many studies on recall do not involve learning new information or skills). Collaborative recall has been studied extensively in past years (for reviews, see Barnier \& 
Sutton, 2008; Blumen et al., 2013; Harris et al., 2008) and has shown benefits for older adults. However, it is not clear whether the same benefits can be found in collaborative learning, and if the mechanisms that make collaborative recall successful are present when learning collaboratively. As such, a review of the literature on collaborative learning may be overdue.

\section{Present research}

A systematic review of the collaborative learning literature specific to older people is timely and important for several reasons. Firstly, from a societal perspective, Western societies are aging, and one in four people is predicted to be aged 65 years or older in the United Kingdom in 2050 (Office for National Statistics, 2021). Because of this increase in population age, age-related cognitive decline will affect more people than ever before. Collaborative learning may offer benefits that can help negate these age-related effects on cognition. In addition, with the rise in population age, people will be required to work longer until they are able to retire. Being able to learn new skills and information is essential to many professions, and as such, research on how to best support older adults in their learning process would benefit both the individual and the workforce.

Secondly, most of the literature has investigated the effects of collaboration on recall, and it is currently unclear whether the same factors are important for collaboration during the acquisition of knowledge. Whereas recall has been well-studied, and reviews on collaborative recall in older age are already available (see Barnier \& Sutton, 2008; Blumen et al., 2013; Harris et al., 2008), as well as a systematic review on preparing for collaborative learning (Mende et al., 2021), there is currently no review on collaborative learning in older age.

Studies on collaborative learning in older age have been scarce, but research on this area has experienced a resurgence in the last two or so decades. However, the existing research on this topic has used a range of methodologies, analyses, and populations, and findings are mixed. As this field of research is expanding, a systematic review of the research on collaborative learning 
can provide a clear, concise overview of the current methods, analyses, and findings. In addition, the proposed systematic review can also identify potential gaps and opportunities for future research to address.

To conclude, we propose a systematic review on collaborative learning in older age to assess the benefits of learning together in negating age-related effects. As studies on collaborative learning in older age are limited and use different designs (i.e., using married couples or younger versus older adults, as well as computerized versus on-paper materials), this systematic analysis will focus on providing a narrative review of the research conducted so far, as well as identify gaps in the current literature. The systematic review will include collaborative learning of new information only, excluding autobiographical (i.e., personal memories) and priorknown semantic information, and explore two research questions; what research has been conducted so far on collaborative learning in older age, and under what circumstances is learning collaboratively more beneficial than learning individually?

\section{Method}

\section{Literature search}

We plan to use the following methods to locate articles examining the topic of collaborative learning in older age:

1. A computerized search on Web of Science, Psychlnfo, PubMed, and Google Scholar for articles on collaborative learning in older age groups. The following keywords would be used (for all searchable fields, such as title, abstract, and keywords): collaborat* learn* OR collaborat* memor* OR "joint referential task" OR "barrier task" AND older age OR 
older adult. Specific to Google Scholar, we will only include the first 5 pages of results ${ }^{1}$. For Prospero and EThOS, we will use fewer keywords as these databases do not accept the use of asterisks. As such, we will use the following keywords: collaborative and older. For an overview of all search terms, see Table 1.

2. A computerized search in PhD thesis libraries, including EThOS and EBSCO Open Dissertations.

3. A manual search by emailing authors to enquire about existing work that has not been published (yet), such as PhD theses or preprints. In addition, we will also contact authors if search results include an abstract or poster that does not have sufficient information to be included as it is.

4. A computerized review of articles cited in papers found in the initial search (1), to determine they fit the inclusion criteria. This search is only conducted on works that have been selected for inclusion after full-text review.

5. A computerized review of articles that have cited the paper found in the initial search (1) that discussed any of the keywords listed above. This search is only conducted on works that have been selected for inclusion after full-text review.

The search terms listed in Table 1 are a combination of key characteristics that each relevant work is required to have and a common type of material that has been used in prior studies on collaborative learning in older age. These terms were not selected through iterative scoping searches. Instead, we selected the search terms initially and then conducted scoping searches to see whether these terms would result in relevant works. Our statement on the progress of the systematic review so far, including details

\footnotetext{
${ }^{1}$ We have chosen to use Google Scholar as a supplementary search engine and to include only the first 5 pages of results, in line with prior work on how best to utilize Google Scholar for systematic reviews (Giustini \& Boulos, 2013; Gusenbauer \& Haddaway, 2020; Haddaway et al., 2015).
} 
on the conducted scoping searches, can be found in the supplementary materials of this manuscript. 


\section{Table 1}

An overview of search terms for each database.

\begin{tabular}{|c|c|c|}
\hline $\begin{array}{l}\text { Database or search } \\
\text { engine }\end{array}$ & Search terms & Type of search \\
\hline Web of Science & $\begin{array}{l}\text { (collaborat* learn* OR collaborat* memor* OR } \\
\text { "joint referential task" OR "barrier task") AND } \\
\text { (older age OR older adult) }\end{array}$ & All fields \\
\hline PubMed & $\begin{array}{l}\text { (collaborat* learn* OR collaborat* memor* OR } \\
\text { "joint referential task" OR "barrier task") AND } \\
\text { (older age OR older adult) }\end{array}$ & All fields \\
\hline Google Scholar & $\begin{array}{l}\text { (collaborat* learn* OR collaborat* memor* OR } \\
\text { "joint referential task" OR "barrier task") AND } \\
\text { (older age OR older adult) }\end{array}$ & All fields \\
\hline Psychlnfo & $\begin{array}{l}\text { (collaborat* learn* OR collaborat* memor* OR } \\
\text { "joint referential task" OR "barrier task") AND } \\
\text { (older age OR older adult) }\end{array}$ & All fields \\
\hline Prospero & Collaborative learning ${ }^{2}$ & All fields \\
\hline EBSCO & $\begin{array}{l}\text { (collaborat* learn* OR collaborat* memor* OR } \\
\text { "joint referential task" OR "barrier task") AND } \\
\text { (older age OR older adult) }\end{array}$ & All fields \\
\hline EThOS & Collaborative learning & All fields \\
\hline
\end{tabular}

\footnotetext{
${ }^{2}$ Both Prospero and EThOS show no results when using the full list of keywords used for other databases, and EThOS does not accept asterisks or the root of words (i.e, collaborat* or collaborat instead of collaborative). In the case of EThOS, this results in some key results being omitted. As such, both databases will be searched with a broader term that allows a higher number return of results.
} 


\section{Inclusion criteria}

1. Works that examine collaborative learning, defined as two or more individuals interacting to jointly acquire new information or a new skill. A distinction is made between collaborative recall and learning; studies examining collaboration only during recall, not as part of collaborative learning, will be excluded.

2. Works that include an older adult population. If studies include two or more populations, one of which are older adults, we will only include information relating to the older adult group (if information regarding the older adult group is clearly separate from any other participant group).

3. Works that include a healthy population (of older adults). If studies include two or more populations, one of which is healthy older adults, we will only include information relating to the healthy older adult group (if the information relating to the healthy sample is available separately).

4. Works that report a healthy older adult sample with a mean age of 60 years or older.

5. Works that provide participants with new information to learn. Some studies have used autobiographical information, which is difficult to verify in terms of how much is remembered or whether the memory is correct, as well as existing semantic information, such as names of US presidents or cities. This type of semantic information is often general knowledge and is known before the commencement of the study. If a work uses both new and existing information and has distinct conditions, we will include it and extract the work on new information only.

6. Types of works included are reviews (e.g., meta-analysis, mini-review, systematic review), research articles, conference proceedings or abstracts, posters, $\mathrm{PhD}$ theses, and preprints. We will also include book chapters but will use these to locate any relevant works discussed in the chapter. 
7. Any works that include the listed criteria above and are written in English.

\section{Exclusion criteria}

1. Works that do not focus on collaborative learning. This also excludes work with a focus only on collaborative recall.

2. Works that do not include an older adult sample.

3. Works that do not include a separate healthy older adult sample (this age group must be clearly distinguishable from other groups).

4. Works with samples of which the mean age is lower than 60 years, or do not clearly state the mean age of the sample.

5. Works that use existing semantic information or personal (i.e., autobiographical) information.

6. Works that are not any of the formats considered appropriate for inclusion (see inclusion criteria 6).

7. Works that are not written in English.

8. Works that do not clearly reference or discuss the materials used in the study/studies.

9. Works that do not clearly mention the type of design that has been used (i.e., a between or within groups design).

10. Works that do not include the statistical outcome(s) or other forms of analysis (some work may be qualitative), or statistical outcomes that cannot be interpreted without needing additional information. For example, a poster or abstract must mention what type of statistical test was used and include the test value, degrees of freedom, and the associated p-value (if frequentist, similar requirements apply for Bayesian analyses). 


\section{Procedure}

\section{Literature research}

We plan to start our literature search by using the listed keywords to search multiple databases for articles relating to collaborative learning in older age. We will also manually search for articles that are either cited in the articles found in the initial literature search, or who have cited the articles found in our initial literature search. Our search may also provide conference abstracts or posters, in which case we will contact the authors to enquire whether any more extensive (unpublished) works are available. In addition, appropriate authors will be contacted for possible unpublished materials. All manual searches will be noted in detail and will be made available for replication purposes. If the proposed systematic review has not been completed in 12 months, we plan to use the same search criteria as we used in our initial search but set the results to most recent, and only include works that were published after our last search date.

\section{Article screening}

Following our literature search, references will be imported into Covidence. We will proceed by screening titles and abstracts. Any works selected at this stage will then be subjected to a fulltext review (step 3). A second reviewer will independently screen $10 \%$ of the articles at both stages to ensure that inclusion criteria are sound. Any initial disagreements on inclusion of the $10 \%$ of works screened by two reviewers will be resolved by a discussion between the primary reviewer (who screens 100\% of works) and the secondary reviewer (who screens $10 \%$ of works). In the case of a discussion between the primary and secondary reviewer not leading to a joint decision, the remaining two co-authors will also provide their decision on whether that work will or will not be included in the systematic review. The decisions made by all involved will be blinded. 


\section{Interpreting selected works}

Lastly, the included works will then be thoroughly compared and contrasted with other included works in terms of their method, area of research within collaborative learning in older age (i.e., participants are spouses, unknown, or young versus older adults), and results (step 4). We plan to make clear distinctions between designs and discuss the findings between different and within similar designs in detail. For example, we will dedicate a section of the manuscript to works on collaborative learning between long-term romantic partners, in terms of how collaborative learning was assessed and whether any benefits were found when long-term romantic partners worked together versus alone. In addition, we will also compare the results of the studies with long-term romantic partners to studies on collaborative learning with strangers and friends. The systematic review may reveal that different designs in collaborative learning research result in varying outcomes (i.e., older adults may perform better in one design compared to another). The proposed approach would give the reader a comprehensive overview of differences between studies that use a similar design (i.e., all using spouses as a learning partner), as well as differences between study designs overall (i.e., studies using spouses or strangers as a learning partner), resulting in detailed knowledge of the work done on collaborative learning in older age thus far. 


\section{Reference list}

Andersson, J., \& Rönnberg, J. (1995). Recall suffers from collaboration: Joint recall effects of friendship and task complexity. Applied Cognitive Psychology, 9(3), 199-211. https://doi.org/10.1002/acp.2350090303

Andersson, J., \& Rönnberg, J. (1996). Collaboration and Memory: Effects of Dyadic Retrieval on Different Memory Tasks. Applied Cognitive Psychology, 10(2), 171-181. https://doi.org/10.1002/(SICI)1099-0720(199604)10:2<171::AID-ACP385>3.0.CO;2-D

Andersson, J., \& Ronnberg, J. (1997). Cued Memory Collaboration: Effects of Friendship and Type of Retrieval Cue. European Journal of Cognitive Psychology, 9(3), 273-287. https://doi.org/10.1080/713752558

Ashby, F. G., Isen, A. M., \& Turken, A. U. (1999). A neuropsychological theory of positive affect and its influence on cognition. Psychological Review, 106(3), 529-550. https://doi.org/10.1037/0033-295x.106.3.529

Barnier, A. J., Harris, C. B., Morris, T., \& Savage, G. (2018). Collaborative Facilitation in Older Couples: Successful Joint Remembering Across Memory Tasks. Frontiers in Psychology, 0. https://doi.org/10.3389/fpsyg.2018.02385

Barnier, A. J., \& Sutton, J. (2008). From individual to collective memory: Theoretical and empirical perspectives. Memory (Hove, England), 16(3), 177-182. https://doi.org/10.1080/09541440701828274

Bärthel, G. A., Wessel, I., Huntjens, R. J. C., \& Verwoerd, J. (2017). Collaboration enhances later individual memory for emotional material. Memory, 25(5), 636-646. https://doi.org/10.1080/09658211.2016.1208248

Berg, C. A., Johnson, M. M. S., Meegan, S. P., \& Strough, J. (2003). Collaborative problemsolving interactions in young and old married couples. Discourse Processes, 35(1), 3358. https://doi.org/10.1207/S15326950DP3501_2 
Blumen, H. M., Rajaram, S., \& Henkel, L. (2013). The applied value of collaborative memory research in aging: Behavioral and neural considerations. Journal of Applied Research in Memory and Cognition, 2(2), 107-117. https://doi.org/10.1016/j.jarmac.2013.03.003

Blumen, H. M., \& Stern, Y. (2011). Short-term and long-term collaboration benefits on individual recall in younger and older adults. Memory \& Cognition, 39(1), 147-154. https://doi.org/10.3758/s13421-010-0023-6

Bopp, K. L., \& Verhaeghen, P. (2005). Aging and Verbal Memory Span: A Meta-Analysis. The Journals of Gerontology: Series B, 60(5), P223-P233. https://doi.org/10.1093/geronb/60.5.P223

Browning, C. A., Harris, C. B., \& Van Bergen, P. (2019). Successful and Unsuccessful Collaborative Processes in Strangers and Couples Performing Prospective Memory Tasks. Discourse Processes, 56(8), 655-674. https://doi.org/10.1080/0163853X.2018.1541398

Canham, M. S., Wiley, J., \& Mayer, R. E. (2012). When Diversity in Training Improves Dyadic Problem Solving. Applied Cognitive Psychology, 26(3), 421-430. https://doi.org/10.1002/acp.1844

Chauvel, G., Maquestiaux, F., Hartley, A. A., Joubert, S., Didierjean, A., \& Masters, R. S. W. (2012). Age Effects Shrink when Motor Learning is Predominantly Supported by Nondeclarative, Automatic Memory Processes: Evidence from Golf Putting: Quarterly Journal of Experimental Psychology. https://journals.sagepub.com/doi/citedby/10.1080/17470218.2011.588714

Comblain, C., D'Argembeau, A., Van der Linden, M., \& Aldenhoff, L. (2004). The effect of ageing on the recollection of emotional and neutral pictures. Memory (Hove, England), 12(6), 673-684. https://doi.org/10.1080/09658210344000477 
Cowan, N. (2014). Working Memory Underpins Cognitive Development, Learning, and Education. Educational Psychology Review, 26(2), 197-223. https://doi.org/10.1007/s10648-013-9246-y

Craik, F. I. M. (2021). Aging II: Later Empirical Work. In Remembering. Oxford University Press. https://doi.org/10.1093/oso/9780192895226.003.0008

Denburg, N. L., Buchanan, T. W., Tranel, D., \& Adolphs, R. (2003). Evidence for preserved emotional memory in normal older persons. Emotion (Washington, D.C.), 3(3), 239-253. https://doi.org/10.1037/1528-3542.3.3.239

Derksen, B. J., Duff, M. C., Weldon, K., Zhang, J., Zamba, K. D., Tranel, D., \& Denburg, N. L. (2015). Older adults catch up to younger adults on a learning and memory task that involves collaborative social interaction. Memory, 23(4), 612-624. https://doi.org/10.1080/09658211.2014.915974

Dillenbourg, P. (1999). Collaborative Learning: Cognitive and Computational Approaches. Advances in Learning and Instruction Series. Elsevier Science, Inc.

Dixon, R. A., \& Gould, O. N. (1996). Adults telling and retelling stories collaboratively. In Interactive minds: Life-span perspectives on the social foundation of cognition (pp. 221241). Cambridge University Press.

Dixon, R., Dixon, K., \& Axmann, M. (2008). Online student centred discussion: Creating a collaborative learning environment.

Duff, M. C., Gallegos, D. R., Cohen, N. J., \& Tranel, D. (2013). Learning in Alzheimer's disease is facilitated by social interaction. The Journal of Comparative Neurology, 521(18), 4356-4369. https://doi.org/10.1002/cne.23433

Duff, M. C., Hengst, J., Tranel, D., \& Cohen, N. J. (2006). Development of shared information in communication despite hippocampal amnesia. Nature Neuroscience, 9(1), 140-146. https://doi.org/10.1038/nn1601 
Elliott, E. M., Cherry, K. E., Brown, J. S., Smitherman, E. A., Jazwinski, S. M., Yu, Q., \& Volaufova, J. (2011). Working Memory in the Oldest-Old: Evidence from Output Serial Position Curves. Memory \& Cognition, 39(8), 1423-1434. https://doi.org/10.3758/s13421-011-0119-7

Evans, I. E. M., Martyr, A., Collins, R., Brayne, C., \& Clare, L. (2019). Social Isolation and Cognitive Function in Later Life: A Systematic Review and Meta-Analysis. Journal of Alzheimer's Disease, 70(1), S119-S144. https://doi.org/10.3233/JAD-180501

Garden, S. E., Phillips, L. H., \& MacPherson, S. E. (2001). Midlife aging, open-ended planning, and laboratory measures of executive function. Neuropsychology, 15(4), 472-482. https://doi.org/10.1037/0894-4105.15.4.472 Giustini, D., \& Boulos, M. N. K. (2013). Google Scholar is not enough to be used alone for systematic reviews. Online Journal of Public Health Informatics, 5(2), 214. https://doi.org/10.5210/ojphi.v5i2.4623

Golbeck, S. L., \& El-Moslimany, H. (2013). Developmental Approaches to Collaborative Learning. In Developmental Approaches to Collaborative Learning (1st ed.). Routledge.

Grady, C. L., Hongwanishkul, D., Keightley, M., Lee, W., \& Hasher, L. (2007). The effect of age on memory for emotional faces. Neuropsychology, 21(3), 371-380. https://doi.org/10.1037/0894-4105.21.3.371

Grégoire, J., \& Linden, M. V. D. (1997). Effect of age on forward and backward digit spans. Aging, Neuropsychology, and Cognition, 4(2), 140-149. https://doi.org/10.1080/13825589708256642 Gusenbauer, M., \& Haddaway, N. R. (2020). Which academic search systems are suitable for systematic reviews or meta-analyses? Evaluating retrieval qualities of Google Scholar, PubMed, and 26 other resources. Research Synthesis Methods, 11(2), 181-217. https://doi.org/10.1002/jrsm.1378 Haddaway, N. R., Collins, A. M., Coughlin, D., \& Kirk, S. (2015). The Role of Google 
Scholar in Evidence Reviews and Its Applicability to Grey Literature Searching. PLOS ONE, 10(9), e0138237. https://doi.org/10.1371/journal.pone.0138237

Hale, S., Rose, N. S., Myerson, J., Strube, M. J., Sommers, M., Tye-Murray, N., \& Spehar, B. (2011). The Structure of Working Memory Abilities across the Adult Life Span.

Psychology and Aging, 26(1), 92-110. https://doi.org/10.1037/a0021483

Halford, G. S., Wilson, W. H., \& Phillips, S. (1998). Processing capacity defined by relational complexity: Implications for comparative, developmental, and cognitive psychology. Behavioral and Brain Sciences, 21(6), 803-831. https://doi.org/10.1017/S0140525X98001769

Harris, C. B., Keil, P. G., Sutton, J., Barnier, A. J., \& Mcllwain, D. J. F. (2011). We Remember, We Forget: Collaborative Remembering in Older Couples. Discourse Processes, 48(4), 267-303. https://doi.org/10.1080/0163853X.2010.541854

Harris, C. B., Paterson, H. M., \& Kemp, R. I. (2008). Collaborative recall and collective memory: What happens when we remember together? Memory (Hove, England), 16(3), 213-230. https://doi.org/10.1080/09658210701811862

Hedden, T., Lautenschlager, G., \& Park, D. C. (2005). Contributions of Processing Ability and Knowledge to Verbal Memory Tasks across the Adult Life-Span. The Quarterly Journal of Experimental Psychology Section A, 58(1), 169-190. https://doi.org/10.1080/02724980443000179

Henkel, L. A., \& Kris, A. (2017). Collaborative Remembering and Reminiscence in Older Adults. In Collaborative Remembering. Oxford University Press. https://doi.org/10.1093/oso/9780198737865.003.0008

Jaroslawska, A. J., Bartup, G., Forsberg, A., \& Holmes, J. (2021). Age-related differences in adults' ability to follow spoken instructions. Memory, 29(1), 117-128. https://doi.org/10.1080/09658211.2020.1860228 
Johansson, N. O., Andersson, J., \& Rönnberg, J. (2005). Compensating strategies in collaborative remembering in very old couples. Scandinavian Journal of Psychology, 46(4), 349-359. https://doi.org/10.1111/j.1467-9450.2005.00465.x

Johansson, O., Andersson, J., \& Rönnberg, J. (2000). Do elderly couples have a better prospective memory than other elderly people when they collaborate? Applied Cognitive Psychology, 14(2), 121-133. https://doi.org/10.1002/(SICI)10990720(200003/04)14:2<121::AID-ACP626>3.0.CO;2-A

Kensinger, E. A. (2008). Age Differences in Memory for Arousing and Nonarousing Emotional Words. The Journals of Gerontology: Series B, 63(1), P13-P18. https://doi.org/10.1093/geronb/63.1.P13

Kim, S., Healey, M. K., Goldstein, D., Hasher, L., \& Wiprzycka, U. J. (2008). Age differences in choice satisfaction: A positivity effect in decision making. Psychology and Aging, 23(1), 33-38. https://doi.org/10.1037/0882-7974.23.1.33

Knight, B. G., Maines, M. L., \& Robinson, G. S. (2002). The effects of sad mood on memory in older adults: A test of the mood congruence effect. Psychology and Aging, 17(4), 653661. https://doi.org/10.1037//0882-7974.17.4.653

Li, S.-C., Lindenberger, U., Hommel, B., Aschersleben, G., Prinz, W., \& Baltes, P. B. (2004). Transformations in the Couplings Among Intellectual Abilities and Constituent Cognitive Processes Across the Life Span. Psychological Science, 15(3), 155-163. https://doi.org/10.1111/j.0956-7976.2004.01503003.x

Li, Y., Baldassi, M., Johnson, E. J., \& Weber, E. U. (2013). Complementary Cognitive Capabilities, Economic Decision-Making, and Aging. Psychology and Aging, 28(3), 595613. https://doi.org/10.1037/a0034172

Martin, M., \& Wight, M. (2008). Dyadic cognition in old age: Paradigms, findings, and directions. In Handbook of cognitive aging: Interdisciplinary perspectives (pp. 629-646). Sage Publications, Inc. https://doi.org/10.4135/9781412976589.n38 
Meade, M. L., Harris, C. B., Van Bergen, P., Sutton, J., \& Barnier, A. J. (Eds.). (2018).

Collaborative remembering: Theories, research, and applications (First edition). Oxford University Press.

Meade, M. L., Nokes, T. J., \& Morrow, D. G. (2009). Expertise promotes facilitation on a collaborative memory task. Memory (Hove, England), 17(1), 39-48. https://doi.org/10.1080/09658210802524240

Mende, S., Proske, A., \& Narciss, S. (2021). Individual preparation for collaborative learning: Systematic review and synthesis. Educational Psychologist, 56(1), 29-53. https://doi.org/10.1080/00461520.2020.1828086

Meudell, P. R., Hitch, G. J., \& Boyle, M. M. (1995). Collaboration in recall: Do pairs of people cross-cue each other to produce new memories? The Quarterly Journal of Experimental Psychology A: Human Experimental Psychology, 48A(1), 141-152. https://doi.org/10.1080/14640749508401381

Myerson, J., Emery, L., White, D. A., \& Hale, S. (2003). Effects of Age, Domain, and Processing Demands on Memory Span: Evidence for Differential Decline. Aging, Neuropsychology, and Cognition, 10(1), 20-27. https://doi.org/10.1076/anec.10.1.20.13454

Nokes-Malach, T. J., Zepeda, C. D., Richey, J. E., \& Gadgil, S. (2019). Collaborative Learning: The Benefits and Costs. In J. Dunlosky \& K. A. Rawson (Eds.), The Cambridge Handbook of Cognition and Education (pp. 500-527). Cambridge University Press. https://doi.org/10.1017/9781108235631.021

Park, D. C., Hedden, T., Davidson, N. S., Lautenschlager, G., Smith, A. D., \& Smith, P. K. (2002). Models of visuospatial and verbal memory across the life span. Psychology and Aging, 299-320.

Pereira-Pasarin, L. P., \& Rajaram, S. (2011). Study repetition and divided attention: Effects of encoding manipulations on collaborative inhibition in group recall. Memory \& Cognition, 39(6), 968-976. https://doi.org/10.3758/s13421-011-0087-y 
Peter-Wight, M., \& Martin, M. (2011). When 2 is Better Than 1 + 1. European Psychologist, 16(4), 288-294. https://doi.org/10.1027/1016-9040/a000024

Rajaram, S. (2017). Collaborative Inhibition in Group Recall: Cognitive Principles and Implications. In Collaborative Remembering. Oxford University Press. https://doi.org/10.1093/oso/9780198737865.003.0004

Romano, J. C., Jr, J. H. H., \& Howard, D. V. (2010). One-year retention of general and sequence-specific skills in a probabilistic, serial reaction time task. Memory, 18(4), 427441. https://doi.org/10.1080/09658211003742680

Salthouse, T. A. (1994). Aging associations: Influence of speed on adult age differences in associative learning. - PsycNET. https://doi.apa.org/doiLanding?doi=10.1037\%2F02787393.20.6.1486

Salthouse, T. A. (1996). The Processing-Speed Theory of Adult Age Differences in Cognition. Psychological Review, 103(3), 403-428.

Salthouse, T. A. (2004). What and When of Cognitive Aging. Current Directions in Psychological Science, 13(4), 140-144. https://doi.org/10.1111/j.0963-7214.2004.00293.x

Salthouse, T. A., Atkinson, T. M., \& Berish, D. E. (2003). Executive Functioning as a Potential Mediator of Age-Related Cognitive Decline in Normal Adults. Journal of Experimental Psychology: General, 132(4), 566-594. https://doi.org/10.1037/0096-3445.132.4.566

Salthouse, T. A., \& Craik, F. I. M. (2007). The Handbook of Aging and Cognition (3rd ed.). Psychology Press.

Schaie, K. W. (1996). Intellectual development in adulthood. In Handbook of the psychology of aging, 4th ed (pp. 266-286). Academic Press.

Selwood, A., Harris, C. B., Barnier, A. J., \& Sutton, J. (2020). Effects of collaboration on the qualities of autobiographical recall in strangers, friends, and siblings: Both remembering partner and communication processes matter. Memory, 28(3), 399-416.

https://doi.org/10.1080/09658211.2020.1727521 
Stephenson, G. M., Wagner, W., \& Brandstatter, H. (1983). An experimental study of social performance and delay on the testimonial validity of story recall. European Journal of Social Psychology, 13(2), 175-191. https://doi.org/10.1002/ejsp.2420130207

Strough, J., \& Margrett, J. (2002). Overview of the special section on collaborative cognition in later adulthood. International Journal of Behavioral Development, 26(1), 2-5. https://doi.org/10.1080/01650250143000300

Vredeveldt, A., van Deuren, S., \& van Koppen, P. J. (2019). Remembering with a friend or a stranger: Comparing acquainted and unacquainted pairs in collaborative eyewitness interviews. Memory, 27(10), 1390-1403. https://doi.org/10.1080/09658211.2019.1662052

Weldon, M. S., \& Bellinger, K. D. (1997). Collective memory: Collaborative and individual processes in remembering. Journal of Experimental Psychology. Learning, Memory, and Cognition, 23(5), 1160-1175. https://doi.org/10.1037//0278-7393.23.5.1160

Williams, L. M., Brown, K. J., Palmer, D., Liddell, B. J., Kemp, A. H., Olivieri, G., Peduto, A., \& Gordon, E. (2006). The Mellow Years?: Neural Basis of Improving Emotional Stability over Age. Journal of Neuroscience, 26(24), 6422-6430. https://doi.org/10.1523/JNEUROSCI.0022-06.2006

Zahodne, L. B., Ajrouch, K. J., Sharifian, N., \& Antonucci, T. C. (2019). Social Relations and Age-Related Change in Memory. Psychology and Aging, 34(6), 751-765. https://doi.org/10.1037/pag0000369

Zunzunegui, M.-V., Alvarado, B. E., Del Ser, T., \& Otero, A. (2003). Social Networks, Social Integration, and Social Engagement Determine Cognitive Decline in CommunityDwelling Spanish Older Adults. The Journals of Gerontology: Series B, 58(2), S93S100. https://doi.org/10.1093/geronb/58.2.S93 